\title{
2 The untellable bisexual asylum stories
}

\author{
Zeynab Peyghambarzadeh
}

\section{Introduction}

Bisexual asylum seekers constitute a very low percentage of LGBT asylum seekers (Rehaag, 2009). While there is not enough data about the percentage of bisexual individuals among the LGBT population of the countries from which most of these asylum seekers come, ${ }^{1}$ some studies claim that the number of individuals who are attracted to people of more than one sex or gender is much higher than the number of gay and lesbian individuals in countries like the United Kingdom and United States (YouGov, 2015a, 2015 b). Although many human rights treaties and conventions such as those of the United Nations High Commissioner for Refugees (UNHCR, 2011, 2012), the Council of the European Union (2004), and USA Citizenship and Immigration Services (2011) claim to support all LGBT asylum seekers, in practice, bisexual asylum seekers' claims may be rejected more than those of lesbian, gay, and trans asylum seekers (Jansen \& Spijkerboer, 2011; LaViolette, 2015; Rehaag, 2009). I review previous studies as well as theoretical discussions on asylum and sexual orientation to explain the untellability of plurisexual stories in the context of seeking asylum based on sexual orientation and discuss how asylum seekers have to perform "refugeeness" and "gay-ness" to fit within a dominant mononormative narrative.

\section{Intimate citizenship of bisexual asylum seekers}

Plummer (2001) suggests the concept of intimate citizenship to discuss the intimate troubles of modern life, including public debates around acceptable forms of sexuality. Plummer (1995, p. 17) defines intimate citizenship as:

A cluster of emerging concerns over the rights to choose what we want to do with our bodies, our feelings, our identities, our relationships, our genders, our eroticisms and our representations.

By referring to the concepts of intimate citizenship, Monro (2015) discusses how not only the dominant heteronormative understanding of citizenship but 


\section{Zeynab Peyghambarzadeh}

even the newer reformist assimilationist homonormative approach to sexual citizenship fail to consider the "fluidity, complexity, and multiplicity" that exist among bisexual citizens (Monro, 2015, p. 142). This homonormative approach advocates for the private sexual rights of same-sex couples in stable monogamous relationships and does not question the heteronormative definition of a "good" citizen. As Monro explains, since bisexual individuals have particular intimate citizenship issues, bisexuality challenges the dominant understanding of sexual citizenship in different ways. First, a considerable number of bisexual individuals are openly non-monogamous, which does not match the dominant monogamous understanding of relationship. Second, the fluidity of their sexuality challenges the dominant static and fixed mononormative understanding of sexual orientations. This mononormative approach prioritises monosexual sexual orientations, including heterosexuality and homosexuality, over plurisexual sexual orientations such as bisexuality, pansexuality, polysexuality, heteroflexibility, homoflexibility, and queer. Third, some bisexual individuals have a queer approach to sexuality, which renders categories of sex, gender, and sexuality fluid or even challenges the relevance of these categories. As Marcus (2018) shows, since bisexual individuals have not been considered in the relevant legal documents, they face more difficulties in claiming their intimate rights compared with monosexual applicants. As a result, bisexual asylum seekers are at a higher risk of losing their chance of being granted asylum based on sexual orientation.

\section{Who is an asylum seeker?}

The history of asylum as a modern concept goes back to the displacement of a large group of Europeans as a result of World War II. After the establishment of the United Nations in 1945, the 1948 Universal Declaration of Human Rights recognised the responsibility of nation states to protect citizens of other nation states, when home countries' governments are not capable or willing to do so. In 1950, the UNHCR was established and the 1951 Refugee Convention. Article $1 \mathrm{~A}(2)$ defines a refugee as a person who is

owing to a well-founded fear of being persecuted for reasons of race, religion, nationality, membership of a particular social group or political opinion ... and is unable or owing to such fear, is unwilling to avail himself to the protection of that country.

(UNHCR, 2010, p. 14)

Since then, there has been constant discussion among the caseworkers in the UNHCR and migration offices of different countries and the applicants, their lawyers, and activists about defining the key concepts of this Article, such as "a well-founded fear", "a particular social group", and a "member" of such a group (Jansen \& Spijkerboer, 2011; Zilli \& Hooper, 2016). 


\section{Sexual orientation-based asylum}

Until the 1980s, sexual orientation was not considered a valid reason to seek asylum, and asylum cases based on sexual orientation could be rejected because attraction towards the same sex was still considered as a "sexual deviation" and a "mental illness" in many countries, including several Western European and North American countries (Bennett, 1999). During the 1980s, some European countries started to recognise gay and lesbian communities as "particular social groups" in need of protection. In 2004, the EU qualification directive in Article 10 clarified that "a particular social group might include a group based on common characteristics of sexual orientation". In 2011, gender identity was added to this Article (Jansen, 2013). In the early 1990s, the United States recognised gays as a particular group with an immutable characteristic and consequently eligible for granting asylum (Shuman \& Bohmer, 2014). Article 16 of the UNHCR guidelines mentions:

A claimant's sexuality or sexual practices may be relevant to a refugee claim where he or she has been subject to persecutory (including discriminatory) action on account of his or her sexuality or sexual practices.

(UNHCR, 2002, p. 4)

Since the 'Guidance Note on Refugee Claims Relating to Sexual Orientation and Gender Identity' (UNHCR, 2012) was published by UNHCR, finding the appropriate methods to assess the credibility of sexual orientation based asylum cases has been a challenge for both UNHCR and migration officers and judges (Hooper, 2016). Since sexual orientation is a private issue, it is hard to prove one's sexuality, and in many cases there is no evidence other than the testimony of the applicant. Consequently, the UNHCR guideline suggests focusing on the identity and life stories of applicants. Telling personal stories during the asylum interview can retraumatize asylum seekers and they have to be able to remember the details and explain them in a specific way to strangers under the pressure of an interview process.

\section{Telling sexual stories in the asylum process}

Different stages of the asylum-seeking process can be viewed as different storytelling occasions (Shuman, 2012). According to Plummer (2001, p. 42), on any storytelling occasion, two main groups are involved. The first group includes story producers who may need to ally with "coaxers, coachers and coercers". Listeners, questioners, coaxers, coachers, and coercers can have an important impact on shifting the stories. The second group includes readers who "consume, interpret and make sense of the stories" (Plummer, 2001, p. 42) and their reactions toward these stories can be under the influence of time, place, and local context as well as the wider context or 


\section{Zeynab Peyghambarzadeh}

"metanarratives". Plummer (2001, p. 44) argues that although stories are changing all the time in the interaction between these two groups, "they can become habitualised and stable". In the asylum interview, as the main storytelling occasion in the asylum process, asylum seekers are storytellers who are trying to tell their stories to the case officers and judges with the help of different groups of "coaxers, coachers and coercers", including other asylum seekers, lawyers, interpreters, and social activists.

My observation in different European and international LGBT seminars and conferences for activists and academics shows that to be supported by advisers, asylum seekers may first need to prove their "gayness" to them. Some LGBT asylum activists think they need to protect the "real gay" asylum seekers and increase their chance of being granted asylum by excluding the "fake" ones from their supportive systems. They can be suspicious that a person who has experienced a sexual or romantic relationship with the other sex may just "lie" about their attraction to same-sex people to take advantage of the asylum system (Peyghambatzadeh, 2019). As a result, the possibility of bisexuality among asylum seekers is often ignored in the discussions around seeking asylum based on sexual orientation. This bi-erasure in the asylum process can result not only from bi-erasure in the heterosexual society, but also from bi-erasure in the gay and lesbian communities. As the coaxers, coachers, and coercers, some monosexual asylum activists, irrespective of their monosexual identity, may reproduce this binary understanding of sexual orientation and look for static or "pure" gay and lesbian identities, desires, and relationship histories. As Shakhsari (2014b) explains, refugee law defines and sanctions a homonormative "immutable" gay identity, which is reproduced by diasporic queer organisations that try to coach the LGBT asylum seekers.

The narratives that asylum seekers use in telling the stories of their sexual orientations are shaped in interaction with advisors. As Plummer explains, "while stories direct us to what is told, narratives tell us how stories are told" (2013, p. 210). Narratives are cultural resources that make negotiation of meaning possible. In each context or framework, dominant narratives provide space for specific stories to be told and understood (Shuman, 2012). Dominant narratives that "silence other voices and render other stories invisible, unreal or unauthentic ... might also 'fix' one identity, at the expense of other possibilities" (Woodiwiss, 2017, p. 14). Narratives enable us to make sense of our lives, but some people do not have access to "easily available stories" to explain their experiences (Woodiwiss, 2017, p. 23). The narrative of the gay asylum seeker has been accepted since 1980s, but being bisexual still can be considered an invalid reason to seek asylum. Consequently, asylum activists and lawyers may advise bisexual applicants to "perform" gayness in their asylum application to increase their chance of being recognised as a "refugee". For instance, Bi UK's (2015) open letter to the parliament mentions that several bisexual asylum seekers in the United Kingdom have received this advice. In addition, multiple subordinate-group 
identities that do not fit the proto-typical individual categories may face invisibility in historical, cultural, political, and legal dominant narratives, which can lead to intersectional invisibility (Purdie-Vaughns \& Eibach, 2008). Bisexual asylum seekers' intimate rights are violated because they are invisible due to their multiple subordinate-group identities. Positioned at the intersection of different inequality systems, including heteronormativity, homonormativity, monosexism, colonialism, and nationalism, it is hard for them to tell their stories and for their audiences to understand and accept them as their stories do not fit the prototypical normative narratives.

Due to mononormative common assumptions, bisexual individuals may pass as heterosexual or gay if they passively or actively "do not use doings, sayings, and material clues to assume membership" of bisexual communities (Maliepaard, 2017, p. 328). They may feel pressured to live a double closet life, as a harm-reduction strategy based on their experiences and expectations of discrimination and lack of acceptance, not only in heterosexual society but also in the gay and lesbian communities (McLean, 2001). This sexual identity-management strategy can result in invisibility of bisexuality. While bisexual asylum seekers may have had to pass as heterosexual to survive in their home countries, they may feel pressured to seek asylum as gay or lesbian to increase their chances of being granted asylum. Asylum seekers who are running away from the regulatory systems of their "home" countries have to perform a "new form of regulation" according to "norms of international refugee regimes and the transitory and destination 'host' states" (Shakhsari, 2014a, p. 99).

Although the asylum law originally was defined to protect European citizens, the UNHCR protocol 1967 Protocol Relating to the Status of Refugees expanded this right to other citizens, as well (UNHCR, 1992). Nowadays, most of the asylum seekers who seek protection based on their sexual orientation are citizens of the so-called "non-Western" countries who seek asylum in the Western European and North American countries. This has contributed to reproduction of the colonial orientalist dichotomy of the backward "East" and progressive "West" (Keely, 2001). As narrators, asylum seekers have to decontextualize their experiences to make their stories understandable for their listeners (Günthner, 2004). Most asylum seekers have to express their sexual orientation with modern "Western" concepts, and sometimes with the medium of an interpreter to be understandable and valid for the case officers. However, they may have a completely different understanding of sexuality in their own culture and language. They are supposed to tell how they have felt and experienced "gayness" in different periods of their lives based on a stereotypical understanding of a "Western" gay individual. Despite diversity within LGBTQ communities, decision-makers have presumptions about queer lifestyle. For instance, it is common to ask the asylum seekers about the gay "scene", assuming all gay people share the same interest in the host country, and the applicants should be interested in doing this and in practising their "freedom" in this new 
“safe" country (Shuman \& Bohmer, 2014). Asylum seekers' claims might be rejected because they are not familiar with the terms and definitions used in Western European and North American countries. This can be harder for applicants such as bisexual asylum seekers, whose sexual orientation is less discussed in society in general. For example,

an applicant in Finland changed his claim from homosexual to bisexual, immediately after he married a woman. Although in the interview he repeatedly pointed out that he is not homosexual, but bisexual, and he held the difference between these two orientations very significant, he did not know the right term for bisexuality, at the time of writing his application. This was not found to be credible and his claim was rejected in 2010.

(Jansen \& Spijkerboer, 2011, p. 59)

Vogl (2013) shows how refugees' stories are assessed based on accidental narrative criteria. She mentions the series of accidents that have an impact on the assessment of these story, including the accident of the decisionmakers who are assigned to the cases, their perceptions of reality, and their expectations of the storytelling process. These expectations are under the influence of the common and culturally accepted stories told in each society. When these stories do not fit the expected narrative, asylum seekers can be in danger of not being believed and consequently not being protected. The asylum process is part of an international system that decides who deserves to be saved and whose life does not matter (Shakhsari, 2014a). As gatekeepers of the national borders, case officers try to assess the asylum stories to find "real gays" as members of particular social groups, with credible cases based on their limited understanding of the country of origin situation.

\section{Membership of a particular social group (PSG)}

In religious or political cases, applicants' opinions or their future plans do not matter. They do not even have to be a member of a group; being perceived by society as such and consequently having a "well-founded fear of persecution" is enough for them to be recognized as a refugee. However, referring to 1951 UN Refugee Convention, sexual orientation-based asylum seekers can be asked to prove membership of a clearly defined group with a common "immutable" characteristic, and being discriminated against due to membership of that particular group, not just being a victim of a single crime (Bennett, 1999; Zilli \& Hooper, 2016).

In addition, what has been criminalized in most countries is same-sex sexual conduct rather than having a specific sexual orientation (Mendos, 2019), and the UNHCR (1992) handbook considers the existence of such a law as a threat to life or freedom and defines it as a form of persecution. On the other hand, the UNHCR guideline (UNHCR, 2012) and many 
regional and national guidelines in Western European or North American countries prevent officers from asking questions about sex, and explicit sex materials cannot be accepted as supportive documents. Instead, officers are supposed to ask questions about feeling and identity, so while applicants can be persecuted for same-sex act, they have to prove that they identify as "gay" to be able to seek asylum.

Interviews with activists and lawyers in different European countries revealed that the decisions of some European migration offices are based on heteronormative and cisnormative dichotomies of "heterosexual vs. homosexual" and "man vs. woman", and the stereotypical assumption that bisexual do not have an "overwhelming and irreversible" desire to engage in sexual relations with a person of the same sex. Hetero-/homosexuality is seen as a stable, normal situation, trans and intersex individuals are pathologized, and bisexual individuals can solve their problems by "choosing" to live as a heterosexual (Jansen \& Spijkerboer, 2011). Since the case officers are looking for a "gay" person with a stable identity, it can be hard for them to consider a bisexual applicant with a fluid sexual orientation as a member of a particular group. They have expectations about a typical gay or lesbian applicant, but to develop stereotypes about bisexual asylum seekers, first they need to recognise bisexuality as a separate and valid sexual orientation (Marcus, 2018). For instance, a Chinese bisexual man's asylum claim was rejected in Australia since the tribunal did not consider bisexuality as a separate sexual orientation, but looked at it as half homosexuality and half heterosexuality. The tribunal wrote:

By stressing at the hearing that he is bisexual, the Applicant has not satisfied the Tribunal that he is reconciled to homosexual activity, lifestyle or even social association, or that he has any kind of preternatural homosexual identity or tendencies. It seems to the Tribunal that if this case were about political opinion, it would be as if the Applicant were saying that, at heart, he was a little bit disposed towards democracy but also eager to support authoritarianism; if it were about religion, it would be as if the applicant, at heart, were a little bit Christian and a little bit atheist. There is significant equivocation in the Applicant's evidence and it goes against him.

(Rehaag, 2009, p. 13, emphasis added)

When an applicant has experienced relationships with people of more than one sex, the case officers may assume that either their same-sex relationships or the other-sex relationships were sham relationships. As a result, the bisexual applicants may lose their chance of being granted asylum (Marcus, 2018). For instance, in the United Kingdom, the Home Office claimed that Orashia Edwards' two-year relationship with his boyfriend in the United Kingdom was a sham relationship, since he had previously been married to a woman (Senzee, 2015). In a similar case in the United States, the immigration 
judge decided that Ray Fuller was not in danger despite providing evidences of being physically attacked and injured due to his same-sex relationship in his country. It seems that the judge was not aware of the definition of bisexuality as she wrote in her decision that Fuller could not be bisexual because he has been married to a woman previously (Marcus, 2018). In several European countries such as Austria, the Netherlands, Finland, and Germany, applicants who used to be married to someone of the other sex or had children were rejected (Jansen \& Spijkerboer, 2011). Rehaag (2009) mentions rejection of several bisexual asylum seekers' cases in Canada for the same reason. In some of these cases, the decision-makers told applicants that they had entered into same-sex relationships because they did not have access to the other-sex partners, or it has been only a "youthful phase". In the United Kingdom, Orashia Edwards was told he had been experimenting in his twoyear relationship with his boyfriend (Senzee, 2015). These assumptions can result from the common binegative believe that bisexuality is just a phase, not a valid, separate sexual orientation.

The fact that decision-makers assume the applicants' sexual orientation by referring to their current or past sexual or romantic relationships shows that they define sexual orientation only in the mononormative binary of heterosexual versus gay. However, sometimes asylum authorities may challenge this binegative assumption in the appeal process. For instance, a Federal Court's decision in Canada in 2004 criticised the adjudicator for not considering the fact that if the applicant were not lesbian, she could be bisexual and even if she were not involved in a same-sex relationship anymore, she could still be in danger due to her previous same-sex relationship. According to the Federal Court:

The claimant feared returning to Hungary because her former common law husband had repeatedly assaulted her after he discovered that she had entered into a relationship with another woman. The adjudicator concluded that the claimant was not a lesbian and no longer involved in a same-sex relationship. The Federal Court concluded that the adjudicator committed an error by omitting to consider the very real possibility that the claimant was bisexual.

(LaViolette, 2015, p. 10)

\section{Credibility}

Different studies show that asylum decisions are arbitrary and based on what seems reasonable to case officers based on their limited knowledge about sexual orientations and the country of origin (Bohmer \& Shuman, 2007; Millbank, 2005, 2009; Murray, 2014). For example, a bisexual female applicant from Ukraine was rejected because the tribunal made assumptions about how many unsuccessful relationships someone could normally have. The tribunal wrote that, "While it is not impossible for someone to be 
bi-sexual it is, on the balance of probabilities, not plausible for the claimant to make three unsuccessful relationships" (Berg \& Millbank, 2009, p. 213). In another case, a Canadian adjudicator found it difficult to believe that an 18-year-old female applicant had not been sexually active in Canada because she used to be sexually active when she was younger. According to the adjudicator:

She [says she] is underage to go to gay clubs and she is busy with going to school. It is difficult to believe how a person sexually active with a male and two females from the age of 14 is living a celibate life now.

(Rehaag, 2009, p. 13)

This expectation can result from the over-sexualisation of young bisexual women. The adjudicator also assumed that the level of applicant's sexual activity could not change over time or in different situations.

\section{Country of origin information}

Case officers are supposed to assess the risk based on country of origin information (COI) documents, which are written by the embassies of Western European or North American countries in the home county of the applicant or by human rights organisations. These documents are usually mostly about gay men, with little written about women or bisexual individuals, which impacts the asylum decisions (Jansen \& Spijkerboer, 2011).

Asylum seekers have to prove having a "well-founded fear of return". Countries where the law does not criminalise same-sex sexual conduct or the law has not been implemented for a long time can be called "safe countries". Consequently, asylum seekers can be sent back to their home countries and be asked to seek state protection or move to another area where people do not know them. In the abovementioned case in Canada in 2004 about a Hungarian asylum seeker, although the Federal Court accepted that the asylum seeker could be at danger due to her previous experience of same-sex relationships, in the end it agreed with the adjudicator that the applicant could seek protection from the Hungarian state instead of seeking protection from the Canadian state. The Federal Court wrote:

The Federal Court was however satisfied that the adjudicator's conclusion that adequate state protection was available in Hungary to abused women and to gays and lesbians should not be disturbed.

(LaViolette, 2015, p. 10)

The current asylum regime is based on a distinction between safe countries, which can protect their citizens, and those that cannot or are not willing to do so, and the assumption that Western European and North American countries can "save" people of colour from the persecution of their governments. 
The relationship between Western European and North American countries and the country of origin can play a huge role in recognising the asylum seeker's fear and defining whether their country is safe (Keely, 2001).

Over the course of the past few decades, there have been ongoing debates among politicians and media of the countries from which sexual orientation-based asylum seekers flee, and those that accept these asylum seekers. In these nationalist postcolonial discursive debates, for antiimperialist politicians and media on one hand, "gayness" is the result of "Westernization" of "Eastern" countries and a threat to their local culture. Gay people are seen as the "other" and it is thought that national identity should be defined through excluding them. On the other hand, for Western European and North American politicians and media, homophobia is a sign of backwardness of "non-Western" countries, rather than a problem that has to be addressed among their citizens (Symons, Altman, \& Norm, 2015).

\section{Hide or seek}

In many cases, asylum seekers not only have to prove their sexual orientation, but also that it has been discovered by others and that they are no longer able to hide it. Disclosure of sexual orientation does not always happen because the person has been seen during a sexual act with someone from the same sex. Sometimes families can become suspicious about a person's sexual orientation simply because they have not married by a certain age (Shuman \& Bohmer, 2014).

Although the UNHCR guidelines (UNHCR, 2012) reject the discretion argument, it is common to suggest to asylum seekers that they should hide their sexual orientation in order to be able to live safely in their home countries (Keenan, 2012). This "solution" can be offered more to bisexual applicants who, according to some case officers, can "choose" to deny their attraction to their same sex. This can be related to invisibility of bisexual individuals in relationship with the other sex and their possibility of passing as heterosexual. For example:

in a case of a bisexual Iranian the court in Austria believed he had "homosexual experiences", but decided that these were not so deeply engraved in his sexual orientation, that it would be impossible for him to live in a heterosexual relationship.

(Jansen \& Spijkerboer, 2011, p. 34)

Jansen (2013) argues that asking asylum seekers to hide their sexual orientation is limiting them from exercising their human rights. According to her, the fact that they have to hide their sexual orientation to be safe means that they are in danger. She suggests considering what could happen to them if others know about their sexual orientation in their home countries. By 
asking bisexual asylum seekers to hide their same-sex sexual conduct and their sexual orientation-based identity in their private spaces, their right to express their identity is denied.

\section{Is the European asylum system becoming more bi-inclusive?}

Jansen's (2019) new study indicates that the chance of bisexual asylum seekers being recognised as refugees has increased in the Netherlands compared with the result of a previous European study (Jansen \& Spijkerboer, 2011). While Jansen and Spijkerboer's (2011) research in different European countries including the Netherlands was mainly based on interviews with lawyers and activists in different organisations, in her recent study Jansen (2019) has analysed the asylum decisions which were made in 2015 and 2016 in the Netherlands. Although there were only 7 bisexual cases among 40 LGBT cases that Jansen reviewed, she concluded that "no examples of stereotypes concerning bisexuals were found in these files" (Jansen, 2019, p. 46). While previous studies showed that some case officers assumed bisexual applicants were not in danger due to their sexual orientation, this study did not find any evidence of rejection of an asylum seeker as a result of questioning their bisexual asylum stories. However, similar to other gay, lesbian, and trans asylum seekers, bisexual asylum seekers' requests have been denied for various reasons - for instance, due to late disclosure of sexual orientation in the asylum application process. In addition, Jansen and Spijkerboer (2011) reveal that case officers were discussing sexual orientation in the binary of homosexual versus heterosexual. However, Jansen (2019) shows that case officers have used the word "bisexual" and "bisexuality" as well. For example, some asylum seekers have been asked: "Are you homosexual or bisexual?" (Jansen, 2019, p. 54). However, Jansen (2019) indicates that the number of bisexual asylum seekers is still lower than the number of gay, lesbian, and trans asylum seekers. Furthermore, as Jansen and Spijkerboer (2011) demonstrate, there have been significant differences between asylum policies of various European countries. Consequently, more studies are needed to see whether the situation has improved in other European countries as well.

It seems that as the bisexual movement is becoming stronger in different countries, the telling and understanding stories of bisexual asylum seekers are becoming easier. The narrative provided by social movements can help individuals to find a name for their personal experiences, connect it with collective experiences, and engage in political actions (Riessman, 1993). In addition to that, as Plummer (2013) mentions, stories are used by social movements and campaigners to help audiences to hear different voices and to sympathise with marginalised groups. Vogl (2013, p. 66) argues that "stories told by or about marginalized or 'outsider' groups can be used to challenge the exclusion of these groups from the law protection". 


\section{Conclusion}

Most of the previous studies that mention bisexual asylum seekers are based on analysing the immigration office's decisions (Hooper, 2016; Rehaag, 2009; Sin, 2015; Vogler, 2016). There are also a few studies that are based on the experiences of experts in Europe (Jansen \& Spijkerboer, 2011) and legal advisers in the United States (Vogler, 2016). These studies focus on how bi-negative attitudes in the assessment of the asylum cases result in the invisibility of bisexual asylum seekers. More studies are needed to collect the asylum stories from the perspective of bisexual asylum seekers in different stages of the asylum process and in various countries.

In this chapter, I have discussed the construction of dominant narratives of sexual orientation in the interactions between asylum seekers and other involved stakeholders in the asylum process. These narratives reflect a mononormative understanding of sexuality due to dominance of the mononormative narratives not only in the heterosexual societies but also in LGBTQ communities. As a result, bisexual asylum seekers feel pressured to reproduce these mononormative narratives in their asylum stories to increase their chance of being granted asylum. This results in bisexual people being limited in exercising their intimate citizenship rights, particularly the rights to freely engage in sexual activities and relationships, choose one's partner(s), and discover, define and express one's sexual identity. Even bisexual individuals who have already been granted asylum may live in fear of being accused of lying about their same-sex attraction if their previous or current relationships with other-sex partners were to be discovered. They can be not only afraid of being questioned by the authorities of the "host" country, but also of being rejected by the LGBT communities of the host country, as well as the diasporic LGBT communities of their "home" country in the host country. Consequently, even after being granted asylum, bisexual individuals may feel pressured to hide their current relationships with their other-sex partners. As a result, their partners may lose the right to remain in the "host" country or the right to family reunion if they are still in their "home" country. In this context, bisexual stories of individuals who have sought asylum based on their sexual orientation may remain untellable forever.

\section{Acknowledgements}

This chapter is based on my ongoing doctoral research at the University of Huddersfield. I would like to thank my supervisors, Professor Surya Monro and Dr Kate Smith, and the editors of this book, Emiel Maliepaard and Renate Baumgartner, for their valuable comments and extraordinary support.

\section{Note}

1 We do not even have information about the percentage of bisexual individuals in the countries where most of the LGTB asylum seekers are heading towards. 


\section{References}

Bennett, A.G. (1999). The 'cure' that harms: Sexual orientation-based asylum and the changing definition of persecution. Golden Gate University Law Review, 29(2), 279-309.

Berg, L., \& Millbank, J. (2009). Constructing the personal narratives of Lesbian, gay and bisexual asylum claimants. Journal of Refugee Studies, 22(2), 195-223. doi: $10.1093 /$ jrs/fep010

Bi UK. (2015). Bisexual asylum seekers. Retrieved from https://bisexualresearch. wordpress.com/2015/05/20/bisexual-asylum-seekers

Bohmer, C., \& Shuman, A. (2007). Rejecting refugees: political asylum in the 21st century. London: Routledge. doi: org/https://doi.org/10.4324/9780203937228

Council of the European Union. (2004). Council Directive 2004/83/EC on minimum standards for the qualification and status of third country nationals or stateless persons as refugees or as persons who otherwise need international protection and the content of the protection granted. Retrieved from https://eur-lex.europa. eu/legal-content/EN/TXT/?uri=celex\%3A32004L0083

Günthner, S. (2004). Narrative reconstructions of past experiences adjustments and modifications in the process of recontextualizing a past experience. In U.M. Quasthoff \& T. Becker (Eds.), Narrative interaction (pp. 285-301). Amsterdam: John Benjamin.

Hooper, L. (2016). Refugee status claims based on sexual orientation and gender identity. Geneva: International Commission of Jurists.

Hooper, L. \& Zilli, L. (2016). Refugee status claims based on sexual orientation and gender identity. Geneva: International Commission of Jurists.

Jansen, S. (2013). Introduction. In T. Spijkerboer (Ed.), Fleeing homophobia, asylum claims related to sexual orientation and gender identity in Europe (pp. 1-31). Oxford: Routledge. doi: 10.1093/ijrl/eev039

Jansen, S. (2019). Assessing LGBTI asylum application in the Netherlands following the $X Y Z$ and $A B C$. Amsterdam: COC Netherlands. Retrieved from www. coc.nl/wp-content/uploads/2019/01/Pride-or-Shame-LGBTI-asylum-in-theNetherlands.pdf

Jansen, S., \& Spijkerboer, T. (2011). Fleeing homophobia: Asylum claims related to sexual orientation and gender identity in Europe. Amsterdam: COC Netherlands, VU University Amsterdam. doi: 10.4324/9780203515723

Keely, C.B. (2001). The international refugee regime(s): The end of the Cold War. International Migration Review, 35(1), 303-14. doi: 10.1111/j.1747-7379.2001. tb00016.x

Keenan, S. (2012). Safe spaces for dykes in danger? Refugee law's production of vulnerable lesbians. In S. Fitzgerald (Ed.), Regulating the international movement of women: From protection to control (pp. 29-47). London: Routledge. doi: $10.4324 / 9780203818381$

LaViolette, N. (2015). Canadian appellate level decisions dealing with refugee claims based on sexual orientation and gender identity - listed according to the definition of a convention refugee. SSRN. doi: 10.2139/ssrn.2594937

Maliepaard, E. (2017). Bisexuality in the Netherlands: Connecting bisexual passing, communities, and identities. Journal of Bisexuality, 17(3), 325-48. doi: 10.1080/ 15299716.2017.1342214

Marcus, N.C. (2018). The global problem of bisexual erasure in litigation and jurisprudence. Journal of Bisexuality, 18(1), 67-85. doi: 10.1080/ 15299716.2017.1384423 


\section{Zeynab Peyghambarzadeh}

Mclean, K. (2001). Living the double life: Bisexual youth speak out. Hecate, 27(1), 109-18.

Mendos, L.R. (2019). State-sponsored homophobia report. Geneva: ILGA. Retrieved from https://ilga.org/downloads/ILGA_State_Sponsored_Homophobia_2019_ light.pdf

Millbank, J. (2005). A preoccupation with perversion: The British response to refugee claims on the basis of sexual orientation, 1989-2003. Social and Legal Studies, 14(1), 115-38. doi: 10.1177/0964663905049528

Millbank, J. (2009). "The ring of truth": A case study of credibility assessment in particular social group refugee determinations. International Journal of Refugee Law, 21(1), 1-33. doi: 10.1093/ijrl/een040

Monro, S. (2015). Bisexuality: Identities, politics and theories. London: Palgrave Macmillan. doi:10.1057/9781137007315

Murray, D.A.B. (2014). Preface to the special issue Queering borders: Language, sexuality and migration. Journal of Language and Sexuality, 3(1), 1-5. doi: 10.1075/ jls.3.1.01mur

Neilson, V. (2005). Homosexual or female - applying gender-based asylum jurisprudence to lesbian asylum. Stanford Law \& Policy Review, 16(2), 417-44. doi: 10.3138/utlj.60.2.315

Peyghambatzadeh, Z. (2019). Why are bisexual asylum seekers almost completely invisible? Retrieved from www.ilga-europe.org/blog/why-are-bisexualasylum-seekers-almost-completely-invisible

Plummer, K. (1995). Telling sexual stories: Power, change, and social worlds. London: Routledge.

Plummer, K. (2001). Documents of life 2: An invitation to a critical humanism (2nd ed.). London: Sage.

Plummer, K. (2013). A manifesto for social stories. In L. Stanley (Ed.), Documents of life revisited: Narrative and biographical methodology for a 21st century critical humanism (pp. 209-20). Aldershot: Ashgate.

Purdie-Vaughns, V., \& Eibach, R. P. (2008). Intersectional invisibility: The distinctive advantages and disadvantages of multiple subordinate-group identities. Sex Roles, 59(5-6), 377-91. doi: 10.1007/s11199-008-9424-4

Rehaag, S. (2009). Bisexuals need not to apply: A comparative appraisal of refugee law policy in Canada, the United States, and Australia. The International Journal of Human Rights, 13(2-3), 1-26. doi: 10.1080/13642980902758226

Riessman, C.K. (1993). Narrative analysis. London: Sage.

Senzee, T. (2015). Bisexual seeking asylum resorts to photos when asked to prove it. The Advocate, 11 May. Retrieved from www.advocate.com/world/2015/05/10/ bisexual-asylum-seeker-humiliated-trying-prove-sexuality-uk-officials- 0

Shakhsari, S. (2014a). Killing me softly with your rights: Queer death and the politics of rightful killing. In S.P. Jin Haritaworn, \& Adi Kuntsman (Eds.), Queer necropolitics (pp. 91-110). London: Routledge. doi: 10.4324/9780203798300

Shakhsari, S. (2014b). The queer time of death: Temporality, geopolitics, and refugee rights. Sexualities, 17(8), 998-1015. doi: 10.1177/1363460714552261

Shuman, A. (2012). Exploring narrative interaction in multiple contexts. In J. Holstein \& J. Gubrium (Eds.), Varieties of narrative analysis (pp. 125-50). London: Sage. doi: $10.4135 / 9781506335117$

Shuman, A., \& Bohmer, C. (2005). Representing trauma: Political asylum narrative. Journal of American Folklore, 117(466), 399-414. doi: 10.1353/jaf.2004.0100 
Shuman, A., \& Bohmer, C. (2014). Gender and cultural silences in the political asylum process. Sexualities, 17(8), 939-57. doi: 10.1177/1363460714552262

Shuman, A., \& Hesford, W.S. (2014). Getting out: Political asylum, sexual minorities, and privileged visibility. Sexualities, 17(8), 1016-34. doi: 10.1177/ 1363460714557600

Sin, R. (2015). Does sexual fluidity challenge sexual binaries? The case of bisexual immigrants from 1967-2012. Sexualities, 18(4), 413-37. doi: 10.1177/ 1363460714550901

Symons, J., Altman, D., \& Norm, I. (2015). International norm polarization: Sexuality as a subject of human rights protection. International Theory, 1(7), 61-95. doi: $10.1017 / \mathrm{s} 1752971914000384$

US Citizen and Immigration Services. (2011). Guidance for adjudicating lesbian, gay, bisexual, transgender, and intersex (LGBTI) refugee and asylum claims: Training module. Retrieved from www.uscis.gov/sites/default/files/USCIS/Humanitarian/ Refugees \%26 Asylum/Asylum/Asylum Native Documents and Static Files/ RAIO-Training-March-2012.pdf

UNHCR. (1992). Handbook on procedures and criteria for determining refugee status under the 1951 convention and the 1967 protocol relating to the status of refugees. Retrieved from www.unhcr.org/4d93528a9.pdf

UNHCR. (2002). Guideline on international protection: Gender-related persecution within the context of Article 1A (2) of the 1951 convention and/or its 1967 protocol relating to the status of refugees. Retrieved from www.unhcr.org/ 3d58ddef4.pdf

UNHCR. (2010). Convention and protocol relating to the status of refugees. Retrieved from https://cms.emergency.unhcr.org/documents/11982/55726/Conv ention+relating +to+the+Status+of + Refugees $+\% 28$ signed $+28+\mathrm{July}+1951 \% 2 \mathrm{C}+\mathrm{e}$ ntered+into+force+22+April+1954\%29+189+UNTS+150+and+Protocol+relatin g+to+the+Status+of+Refugees+\%28signed $+31+$ January $+1967 \% 2 \mathrm{C}+$ ent

UNHCR. (2011). Working with lesbian, gay, bisexual transgender $\&$ intersex persons in forced displacement. Retrieved from www.refworld.org/docid/4e6073972.html

UNHCR. (2012). Guideline on International Protection No. 9: Claims to Refugee Status Based on Sexual Orientation and/or Gender Identity within the context of Article 1A(2) of the 1951 Convention and/or its 1967 Protocol Relating to the Status of Refugees. Retrieved from www.unhcr.org/509136ca9.pdf

Vogl, A. (2013). Telling stories from start to finish: Exploring the demand for narrative in refugee testimony. Griffith Law Review, 22(1), 63-86. doi: 10.1080/ 10383441.2013.10854767

Vogler, S. (2016). Legally queer: The construction of sexuality in LGBQ asylum claims. Law and Society Review, 50(4), 856-89. doi: 10.1111/lasr.12239

Woodiwiss, J. (2017). Challenges for feminist research: Contested stories, dominant narratives and narrative frameworks. In J. Woodiwiss, K. Smith, \& K. Lockwood (Eds.), Feminist narrative research: Opportunities and challenges (pp. 13-37). London: Palgrave Macmillan. doi: 10.1057/978-1-137-48568-7_2

YouGov. (2015a). 1 in 2 young people say they are not $100 \%$ heterosexual. Retrieved from https:/yougov.co.uk/topics/lifestyle/articles-reports/2015/08/16/ half-young-not-heterosexual

YouGov. (2015b). A third of young Americans say they aren't $100 \%$ heterosexual. Retrieved from https://today.yougov.com/news/2015/08/20/third-youngamericans-exclusively-heterosexual/ 